\section{Original} article

\title{
STD history, self treatment, and healthcare behaviours among fishermen in the Gulf of Thailand and the Andaman Sea
}

\author{
Achara Entz, Vipan Prachuabmoh, Frits van Griensven, Varda Soskolne
}

Objective: Migrant populations are at higher risk for HIV infection. Access to health care and STD treatment is thought to lower this risk. This study aims to examine determinants of STD history and treatment and healthcare behaviours among fishermen in the Gulf of Thailand and the Andaman Sea.

Methods: A cross sectional survey of fishermen working on commercial fishing trawlers was conducted in four provinces in Thailand in early 1998.

Results: Of the 818 fishermen interviewed, 30\% reported a history of STD, of which $31 \%$ reported self treatment of the last STD. 32\% reported self care for general health while ashore. In multivariate analyses, a history of STD was significantly more often reported by older men compared with younger men, by owners and skippers compared with lower positions on the boat, and by men who have ever visited female sex workers. Self treatment of the last STD was related to being Burmese compared with being Thai, and to working as a steersman or ship hand compared with as a skipper. Self care for general health while ashore was significantly related to being Burmese or Khmer compared with being Thai, and to being unmarried compared with married.

Conclusion: Burmese migrant fishermen and their needs should be targeted for culturally specific interventions to increase their understanding of STD treatment and improve their access to health care.

(Sex Transm Inf 2001;77:436-440)

Keywords: sexually transmitted diseases; migrants; South East Asia

\section{Introduction}

Migration is a worldwide phenomenon. More people around the world move for all sorts of reasons, particularly to escape economic deprivation. ${ }^{1}$ This process is often viewed as south to north migration, from the developing world to the industrialised world. However, the most socially significant migration is occurring within or between developing countries in Asia and Africa. ${ }^{2}$ People move mostly in search of unskilled jobs and often have legal and economic problems that limit their access to health care, with potential risk to their health. In Thailand, labour migration is common, and its large fishing industry attracts many internal and external migrant workers. More than half of the 161667 registered fishermen were employees (not family members), of whom about $42 \%$ were migrants from either inside or outside Thailand (12 750 from Burma and Cambodia). ${ }^{3}$ These figures are likely to be an underestimate. Many go uncounted, since there is a considerable turnover and a high number of illegal immigrants among fishermen. Even though the majority of Thai fishing boats operate inside Thai waters (the Gulf of Thailand and the Andaman Sea), many go out for a considerable time and fish in waters of other countries in the region. ${ }^{3}$

Compared with other occupations of migrant workers, fishermen are even more mobile. Most of them are young men who come on their own, without their families, to look for a job, usually as unskilled labourers.
They may shift work locations and boat owners in search of better work, far from their home towns and families. Those who work on deep sea fishing vessels stay out at sea for prolonged periods of time-several weeks or months. When they arrive ashore, they often engage in intense alcohol consumption and sexual risk behaviour, as they have only limited time available before departing for another long voyage at sea. ${ }^{45}$ While high risk sexual behaviours and alcohol consumption are common among internal migrants in Thailand, ${ }^{67}$ fishermen may be particularly at risk. Their harsh and boring working conditions at sea, their recreational activities while on shore, and the distance from their wives and families make fishermen vulnerable to sexually transmitted diseases (STDs), a major risk factor for HIV infection. STD rates have been continuously declining in Thailand, dropping from 7.43 reported cases per 1000 people in 1988 to only 0.27 cases per 1000 people in $1999 .{ }^{8}$ However, in the countries of origin of many migrant fishermen, Cambodia or Myanmar (Burma), the available information indicates higher rates compared with Thailand. $^{9}{ }^{10}$ Little is known about STD history and treatment behaviours among fishermen.

Access to health care may be difficult for fishermen not only while at sea, but also when they are ashore. Because of their mobility, they may not know the services available on shore and may have a lower use of primary health care and STD services. This can be particularly crucial in case of an untreated STD. A study 
Table 1 Factors associated with STD history

\begin{tabular}{|c|c|c|c|c|}
\hline \multirow[b]{2}{*}{ Characteristic } & \multicolumn{2}{|c|}{ Bivariate } & \multicolumn{2}{|l|}{ Multivariate } \\
\hline & No & $\%$ ever $S T D$ & $O R$ & $95 \% C I$ \\
\hline \multicolumn{5}{|l|}{ Nationality } \\
\hline Khmer & 98 & 23.5 & 0.77 & $0.45-1.32$ \\
\hline Burmese & 135 & 11.1 & 0.54 & $0.29-1.01$ \\
\hline Thai & 577 & $35.5^{\star \star \star}$ & 1 & - \\
\hline \multicolumn{5}{|l|}{ Age } \\
\hline 32 or less & 540 & 21.9 & 0.51 & $0.35-0.75$ \\
\hline 33 or older & 269 & $46.5^{\star \star \star}$ & 1 & - \\
\hline \multicolumn{5}{|l|}{ Marital status } \\
\hline Unmarried & 491 & 23.0 & 0.69 & $0.47-1.00$ \\
\hline Married & 319 & $40.8^{\star \star \star}$ & 1 & - \\
\hline \multicolumn{5}{|l|}{ Education (years) } \\
\hline Less than 5 & 355 & 33.8 & & \\
\hline $5-6$ & 258 & 27.9 & & \\
\hline 7 or more & 196 & 26.0 (n.s.) & Not included & \\
\hline \multicolumn{5}{|l|}{ Average duration at sea } \\
\hline Up to 2 months & 715 & 30.5 & & \\
\hline 3 months or more & 94 & 26.6 (n.s.) & Not included & \\
\hline \multicolumn{5}{|l|}{ Position on the boat } \\
\hline Steersman, ship hand & 632 & 25.2 & 0.56 & $0.38-0.84$ \\
\hline Owner, skipper & 163 & $51.5^{\star \star \star}$ & 1 & - \\
\hline \multicolumn{5}{|l|}{ Ever sex with FSW } \\
\hline No & 181 & 4.4 & 1 & - \\
\hline Yes & 623 & $37.7^{\star \star \star}$ & 9.95 & $4.70-21.07$ \\
\hline
\end{tabular}

among young northern Thai military conscripts found that men tried to protect themselves from STDs and HIV with "over the counter" antibiotics. ${ }^{11}$ Likewise, in a study in female sex workers in Chiang Rai, Thailand, self medication for treatment and prevention of STDs was common. ${ }^{12}$ The difficulties in accessing healthcare services may be even greater for migrant fishermen from neighbouring countries, because of language and cultural barriers or their legal status in Thailand. ${ }^{13}$ They may therefore tend to self care when symptoms appear.

An elevated risk for STDs and HIV was previously observed in other mobile populations, such as merchant vessel crews and truckers, who were found to be a link in the spread of HIV among different locations. ${ }^{14}{ }^{15}$ Fishermen can also connect to such networks-from the higher HIV prevalence areas of the ports to their sexual networks in their home towns. However, few data are available so far on their health seeking patterns and STD history and treatment that may put fishermen at greater risk for HIV infection.

As part of a study on health and sexual behaviour of fishermen in Thailand, the present report focuses on STD history and treatment, healthcare seeking behaviours, and their associations with demographic and occupational characteristics.

\section{Material and methods}

STUDY POPULATION AND DATA COLLECTION PROCEDURES

This cross sectional survey consisted of face to face interviews conducted between January and April 1998 in four coastal provinces of Thailand: Traat (the eastern Gulf of Thailand), Samut Sakhon (the inner Gulf), Songkhla (the southern Gulf), and Ranong (the west, the Andaman Sea). These provinces cover all coastal areas of Thailand and reflect the different ethnic compositions of the fisherman population (Khmer in the eastern, Thai in the central, and Burmese in the southern and western regions). Eligible for enrolment were men working on commercial fishing vessels of 10 or more tons that go out to sea for at least 10 days (Samut Sakhon, Songkhla, Ranong) or at least 5 days (Traat, as its fishing grounds are closer to shore). These criteria were used to avoid the enrolment of subsistence fishermen. Our subjects were recruited from boats that were ashore. After owners or captains gave permission to interview their crew, crew members who provided verbal informed consent were interviewed anonymously. Thai, Khmer, and Burmese speaking interviewers administered the questionnaires. Cooperation from fishery officials, owners, and crew members was excellent and refusal to participate was rare.

\section{STUDY VARIABLES}

There are three dependent variables used for the present analysis, including (a) STD history, whether they had ever had an STD in their lifetime, and if yes, what symptoms; (b) STD treatment, for the most recent episode of STD, dichotomised into "self care" only (for example, doing nothing, taking their own medicine, getting medicine from friends or the skipper, getting traditional medicine, and going to a pharmacy) or "use health services" (for example, going to an STD clinic or hospital); (c) healthcare seeking behaviours, self treatment or approaching others while ill at sea or on shore for a couple of days, dichotomised into "self care" (for example, sleeping, taking their own medicine, getting medicine from friends or the skipper, getting traditional medicine, and going to a pharmacy) or "use health services" (for example, going to a clinic/hospital). If they reported using clinics or hospitals, they were assigned to "use health services" even if they also reported self care above in both treatment method variables.

Sociodemographic variables (nationality, age, marital status, and years of education) and occupational variables (duration of working as a fisherman and position on the boat) were used as predictors; meanwhile sex with a female sex worker (FSW) (ever) was classified as either "yes" or "no" (as a risk factor for STD history).

\section{STATISTICAL ANALYSIS}

Bivariate associations of demographic and occupational characteristics with healthcare seeking and STD history were examined using the $\chi^{2}$ test. Multivariate logistic regression analyses was performed in order to examine the independent relations of these variables.

\section{Results}

SOCIODEMOGRAPHIC CHARACTERISTICS

Of the 818 fishermen in this study, $582(71 \%)$ were Thai (of which $75 \%$ were internal migrants), 137 (17\%) were Burmese, and 99 $(12 \%)$ were Khmer. The majority of the fishermen were young $(67 \%$ were age 32 or younger), with low education ( $44 \%$ had studied for less than 5 years), and unmarried $(61 \%)$. They worked as fishermen for less than 11 years $(67 \%)$, worked in lower positions (44\% as a ship hand and $36 \%$ as a steersman/ mechanic), and were going out to sea for 2 
Table 2 Factors associated with self treatment of last STD

\begin{tabular}{|c|c|c|c|c|}
\hline \multirow[b]{2}{*}{ Characteristic } & \multicolumn{2}{|c|}{ Bivariate } & \multicolumn{2}{|l|}{ Multivariate } \\
\hline & No & $\begin{array}{l}\% \text { Self care of } \\
\text { STD }\end{array}$ & $O R$ & $95 \% C I$ \\
\hline \multicolumn{5}{|l|}{ Nationality } \\
\hline Khmer & 23 & 30.4 & 0.84 & $0.32-2.24$ \\
\hline Burmese & 15 & 66.7 & 4.07 & $1.30-12.77$ \\
\hline Thai & 205 & $27.8^{\star \star}$ & 1 & - \\
\hline \multicolumn{5}{|l|}{ Age } \\
\hline 32 or less & 118 & 36.4 & 1.55 & $0.87-2.78$ \\
\hline 33 or older & 125 & $24.8^{\star}$ & 1 & - \\
\hline \multicolumn{5}{|l|}{ Marital status } \\
\hline Unmarried & 113 & 35.4 & & \\
\hline Married & 130 & $26.2(\mathrm{~ns})$ & Not included & \\
\hline \multicolumn{5}{|l|}{ Education (years) } \\
\hline Less than 5 & 120 & 29.2 & & \\
\hline $5-6$ & 72 & 36.1 & & \\
\hline 7 or more & 51 & $25.5(\mathrm{~ns})$ & Not included & \\
\hline \multicolumn{5}{|l|}{ Average duration at sea } \\
\hline $\mathrm{Up}$ to 2 months & 218 & 28.9 & & \\
\hline 3 months or more & 25 & $44.0(\mathrm{~ns})$ & Not included & \\
\hline \multicolumn{5}{|l|}{ Position on the boat } \\
\hline Steersman, ship hand & 159 & 37.1 & 2.44 & $1.26-4.73$ \\
\hline Owner, skipper & 84 & $17.9^{\star \star}$ & 1 & - \\
\hline \multicolumn{5}{|l|}{ Ever sex with FSW } \\
\hline No & 8 & 25.0 & & \\
\hline Yes & 235 & 30.6 (ns) & Not included & \\
\hline
\end{tabular}

†Only for men who reported a history of STD, $n=243$.

${ }^{\star} \mathrm{p}<0.05,{ }^{\star \star} \mathrm{p}<0.01,{ }^{\star \star \star} \mathrm{p}<0.001$.

Table 3 Factors associated with health care while ashore

\begin{tabular}{|c|c|c|c|c|}
\hline \multirow[b]{2}{*}{ Characteristic } & \multicolumn{2}{|c|}{ Bivariate } & \multicolumn{2}{|l|}{ Multivariate } \\
\hline & No & $\%$ Self care & $O R$ & $95 \% C I$ \\
\hline \multicolumn{5}{|l|}{ Nationality } \\
\hline Khmer & 99 & 46.5 & 2.21 & $1.40-3.48$ \\
\hline Burmese & 137 & 44.5 & 1.98 & $1.33-2.95$ \\
\hline Thai & 582 & $27.1^{\star \star \star}$ & 1 & - \\
\hline \multicolumn{5}{|l|}{ Age } \\
\hline 32 or less & 547 & 36.4 & 1.05 & $0.71-1.54$ \\
\hline 33 or older & 270 & $24.1^{\star \star \star}$ & 1 & - \\
\hline \multicolumn{5}{|l|}{ Marital status } \\
\hline Unmarried & 497 & 39.2 & 1.84 & $1.27-2.66$ \\
\hline Married & 321 & $21.8^{\star \star \star}$ & 1 & - \\
\hline \multicolumn{5}{|l|}{ Education (years) } \\
\hline Less than 5 & 359 & 33.1 & & \\
\hline $5-6$ & 262 & 31.7 & & \\
\hline 7 or more & 196 & 31.6 (n.s.) & Not included & \\
\hline \multicolumn{5}{|l|}{ Average duration at sea } \\
\hline Up to 2 months & 721 & 32.9 & & \\
\hline 3 months or more & 96 & 29.2 (n.s.) & Not included & \\
\hline \multicolumn{5}{|l|}{ Position on the boat } \\
\hline Steersman, ship hand & 640 & 35.0 & 1.49 & $0.95-2.34$ \\
\hline Owner, skipper & 163 & $19.6^{\star \star \star}$ & 1 & - \\
\hline
\end{tabular}

${ }^{\star} \mathrm{p}<0.05,{ }^{\star \star} \mathrm{p}<0.01,{ }^{\star \star \star} \mathrm{p}<0.001$

weeks to 2 months (47\%). Nationality was significantly related to age $(28 \%, 41 \%$, and $50 \%$, of Thai, Khmer, and Burmese men, respectively, were less than 25 years of age, $p<0.001$ ) and more Thai men were married, worked for longer period as fishermen, and had higher positions on the boats.

STD HISTORY

Thirty per cent of fishermen in this study reported that they had ever had an STD in their lifetime. STD symptoms reported by these men were urethral discharge $(84 \%)$, genital ulcers $(41 \%)$, and genital warts $(10 \%)$. A history of STD was reported more often by Thai fishermen (compared with Khmer or Burmese), by men age 33 or older (compared with younger), by married men, by skippers or owners (compared with steersmen/mechanics or ship hands), and those who reported visiting FSWs (table 1). No associations with education or duration at sea were found. In multivariate analysis, a history of STDs was significantly more often reported by older men compared with younger men, by owners and skippers compared with lower positions on the boat, and by men who had ever visited an FSW compared with those who had not (table 1).

STD TREATMENT

Among the fishermen who reported a lifetime history of STD ( $n=243)$, about one third said they took care of their last STD by themselves. Self treatment of STD was significantly more frequent among Burmese compared with Khmer or Thai, among men age 32 or less (compared with being older), and among steersmen or ship hands compared with skippers, but was not related to education, marital status, or duration at sea (table 2). In multivariate analysis, Burmese fishermen were four times as likely as Thai fishermen to self treat their last reported STD, and those working as a steersman or a ship hand were more than twice as likely to self treat themselves compared with skippers.

Many (58\%) fishermen who said they received drugs from either non-health professionals or health professionals, could not name the drug they used. The others used aminoglycoside $(14 \%)$, rifampicin $(11 \%)$, chloramphenicol $(6 \%)$, or tetracycline $(5 \%)$, and the rest used other agents. A majority of the respondents $(85 \%)$ said they took all the medicines prescribed to them. Sixty eight per cent stated that they had certain techniques they used to protect themselves against infection with STD. These included safer methods such as condom use $(77 \%)$ and no sex or no CSW patronisation (9\%), but also less proved methods, such as taking medicines before or after sex $(7 \%)$, cleaning their genitals after sex with water or soda water $(2 \%)$, urination $(1 \%)$, and other unreliable methods (selecting clean women, fewer CSW visits, exercise, not kissing partners) $(4 \%)$.

\section{HEALTHCARE BEHAVIOUR}

Self care was common when the fishermen felt sick for a couple of days while at sea $(69 \%)$, but was lower (32\%) while ashore. In bivariate analysis, self care while ashore was significantly related to fishermen's nationality (Burmese or Khmer compared with Thai), age (32 or less compared with being older), marital status (unmarried), and position on the boat (a steersman/mechanic or a ship hand compared with a skipper), but not to education or average duration at sea (table 3). In multivariate analysis, self care while ashore was significantly related to nationality - it was double among the Burmese and more than double among the Khmer compared with the Thai and was almost double among unmarried compared with married fishermen after controlling for other variables (table 3 ).

\section{Discussion}

This study of migrant fishermen shows that a history of STD was related to older age and a higher position on the boat. Self care of STD was related to being Burmese and having a lower position on the boat. Additionally, it 
demonstrates that foreign fishermen, particularly Burmese, are those with less access to health care compared with their Thai counterparts. Instead, they tend to perform self care and self treatment, particularly regarding STDs, which places them at higher risk for HIV infection.

The associations of a history of STD with older age and higher position on the boat and with having visited female sex workers are expected. Since those who are younger and less trained may have entered the fishing industry more recently, they are less likely to have STD experience. However, this may also represent a cohort effect, as STD rates in Thailand have dropped in the $1990 \mathrm{~s}$, partly due to the campaign for $100 \%$ condom use in commercial sex work. ${ }^{16-18}$

Self treatment and self prophylactic behaviours are common in Thailand, where antibiotics and other drugs are relatively inexpensive, widely available, and sold without prescription in pharmacies throughout the country. Khamboonruang et $a l^{11}$ have shown that nonprescription drugs are commonly used by young men to protect themselves from STD infection. Informal conversations we had with boat skippers or owners revealed that they prepared a set of basic medications for use in the boats; these include first aid kits and pain relievers. Kanamycin (an antibiotic) injections were also reported to be available on the boats. ${ }^{19}$ These supplies can be a primary source of care, free of charge for fishermen, and may partially explain the higher rates of self care among migrants who usually tend to avoid authorities.

Our findings show that the risk for self care was higher among Burmese fishermen than among Thais (after controlling for the confounding effects of age and position on the boat). This suggests that Burmese migrants may have greater language, cultural, and/or legal barriers; it is difficult for these migrant workers to access these services. A similar association was found among female sex workers in Chiang Rai, where those of non-Thai origin (mostly Burmese) were significantly more likely to perform self medication for the prevention and treatment of STDs. ${ }^{12}$ Other surveys have shown the role of government healthcare delivery, as well as individual and cultural factors in the use of services by migrants in Thailand. For example, provincial public health departments in coastal provinces cannot provide prevention and care services to migrants, since the budget is calculated on the basis of the official resident population. Even though some Burmese migrants actually receive care in public health facilities for humanitarian reasons, the budget for this service is derived from income generated by health insurance cards purchased only by legal Burmese workers. ${ }^{20}$ In some areas specific clinics have been established by non-governmental organisations to provide care to foreign workers, irrespective of their legal status, but access is still limited. STD services are harder to access than general health services. Our findings confirm previous reports that Burmese migrants treat themselves with oral drugs and seek injections of popular antibiotics for many types of infections, including STD. ${ }^{19}$ If treatment is not effective, they seek injection at a clinic or the hospital, usually preferring to use private clinics over government hospitals. ${ }^{21}$ Cost of treatment can also become a barrier since services of private clinics are normally more expensive than those of the government. The Thai-Burmese language barrier may further complicate access to health care by Burmese workers. Many of them originate from distinct ethnic groups within Burma and may not be able to communicate fluently in Burmese, let alone in Thai. Finally, the scarcity of free health care in Burma during their pre-migration time may also explain their reliance on self care.

The position of Khmer migrant fishermen with regard to access to health care, especially for STDs, is better compared with their Burmese counterparts. Cross border movement between Thailand and Cambodia has few legal obstacles, and migrant workers pass over freely. Since the Khmer language is linguistically closer to Thai than is Burmese, many Khmer fishermen can communicate in Thai, which facilitates their access to services. Also, several Thai public health workers in these geographic areas may be able to speak Khmer or Khmer based dialects or may be ethnically Khmer. ${ }^{4}$

It should be noted that we collected our data during the peak of an economic crisis in Thailand and neighbouring countries that started to have some effect on health services. ${ }^{18}$ It might have further reduced the access of migrant fishermen to STD care services.

The findings of self care of STDs should be considered with some caution, as only a small number of Burmese and Khmer reported a history of STD. A sequence of how these fishermen search for treatment could not be ascertained from our data, since we asked for the methods they used for their previous STD only. Although they were considered health service users, they can also practise self care. In addition, STD history was based on self reporting; in reality, there might be either more or fewer fishermen who actually had an infection with STD.

In conclusion, Burmese fishermen have lower access to health care in general and to STD treatment in particular than their Thai and Khmer counterparts. It is therefore important to target Burmese fishermen with culturally specific interventions to increase their understanding of STD treatment and to improve their access to health care. This in turn will help to halt the spread of STD and HIV among this vulnerable migrant population.

This paper was presented in part at the Fifth Asia-Pacific Social Science and Medicine Conference, 24-28 September 2000, Kandy, Sri Lanka.

Dr van Griensven is currently with the HIV/AIDS Collaboration, Thai Ministry of Public Health and US Centers for Disease Control and Prevention, Nonthaburi, Thailand.

Sponsorship: Supported by the Netherlands Israel Research Sponsorship: Supported by the Netherlands Israel
Development Programme (NIRP, project no 95-8.3)

We are grateful to the staff of the College of Population Studies, Chulalongkorn University, Bangkok, Thailand; the officials 
of the Thai ministries of Agriculture and Cooperatives and of Public Health; the national and provincial fishing associations; the World Vision Foundation of Thalland, and our interviewers. Finally, we would like to express our gratitude to the owners,
captains, and crews of the fishing vessels for their support of the

captain
study.

Contributors: VS, FvG, and VP were responsible for design of the study, study coordination, and writing the manuscript; $\mathrm{AE}$ was responsible for data collection, statistical analysis, and writing the manuscript.

1 Weeks JR. Population: an introduction to concept and issues. 6th ed. Belmont: Wadsworth Publishing, 1996.

2 Carballo M, Siem H. Migration, migration policy and AIDS. In: Haour-Knipe M, Rector R, eds. Crossing borders: migration, ethnicity and AIDS. London: Taylor \& Francis, 1996.

3 National Statistical Office. The 1995 marine fishery census whole kingdom. Bangkok: Office of the Prime Minister and Department of Fisheries, Ministry of Agriculture and Cooperatives, 1997.

4 Pramualratana A, Somrongthong $\mathrm{R}$, Jindasak $\mathrm{K}$, et al. Assessment of the potential for spread and control of HIV among cross-border populations along the Thai-Cambodian border cross-border populations along the Thai-Cambodian border. Social Research Mahidol University, 1995. 5 Komonbut R. Thai fishermen and their local contacts in Irian faya: an assessment of issues related to the spread of HIVIAIDS
in Merauke. Jakarta: Program for Applied Technology in
Health (PATH), 1995 .

6 Maticka-Tyndale E, Elkins D, Haswell-Elkins M, et al. Contexts and patterns of men's commercial sexual partnerships in northeastern Thailand: implications for AIDS prevention. Soc Sci Med 1997;44:199-213.

7 Vanlandingham M, Knodel J, Saengtienchai C, et al. In the company of friends: peer influence on Thai male extramarital sex. Soc Sci Med 1998;47:1993-2011.

8 Venereal Diseases Division Department of Communicable Diseases. Report on venereal diseases control, fiscal year 1999. Bangkok: Venereal Diseases Division, 2000. (In Thai)

9 World Health Organization Regional Office for the Western Pacific. Developing estimates for curable STIs in selected countries of the Western Pacific Region. STI/HIV/AIDS surveillance report, special edition. 1999;14:22-4.

10 Department of Health. Sexually transmitted diseases and skin diseases control programme, annual report. Yangon: Disease
Control Programme Department of Health, 1992 cited in Htoon MT, Lwin HH, San KO, et al. HIV/AIDS in Myanmar. AIDS 1994;8 (suppl 2):s105-9.

11 Khamboonruang C, Beyrer C, Natpratan C, et al. Human immunodeficiency virus infection and self-treatment for sexually transmitted diseases among Northern Thai Men. Sex Transm Dis 1996;23:264-9.

12 Kilmarx P, Limpakarnjanarat $\mathrm{K}$, St Louis $\mathrm{M}$, et al. Medication use by female sex workers for treatment and prevention of sexually transmitted diseases, Chiang Rai, Thailand. Sex Transm Dis 1997;24:593-8.

13 Chantavanich S, Beesey A, Amaraphibal A, et al. Cross-border migration and HIV vulnerability at the Thai-Cambodia border: Aranyaprathet and Khlong Yai. Bangkok: The Asian Research Center for Migration Institute of Asian Studies, 1999.

14 Jenkins C. Behavioral risk assessment for HIVIAIDS among workers in the transport industry, Papua New Guinea. Goroka: Papua New Guinea Institute of Medical Research,1994.

15 Podhisita C, Wawer MJ, Pramualratana A, et al. Multiple sex partners and condom use among long distance truck drivers in Thailand. AIDS Educ Prev 1996;8:490-8.

16 Hanenberg R, Rojanapithayakorn W, Kunasol P, et al. Impact of Thailand's HIV-control programme as indicated by the decline of sexually transmitted diseases. Lancet 1994;344:243-5.

17 Phoolcharoen W, Ungchusak K, Sittitrai W, et al. Thailand lessons from a strong national response to HIV/AIDS. Nonthaburi: Communicable Disease Control Department, AIDS Division, 1998.

18 Tangcharoensathien V, Harnvoravongchai P, Pitayarangsarit $\mathrm{S}$, et al. Health impact of rapid economic changes in Thailand. Soc Sci Med 2000;51:789-807.

19 UNICEF/UNAIDS. A sub-national study: profiling the maritime industry $\mathcal{E}$ responses to HIV and drug use among seafarers in Ranong Thailand. Bangkok: UNICEF East Asia and Pacific Regional Office, 1999

20 Prachuabmoh V, Chongwatana N, Wongboonsin P, et al. Impact of migration on the status of international migrants. CPS Publication No 283. Bangkok: Chulalongkorn University, 2001 (in Thai).

21 Care Thailand/Raks Thai Foundation. Migrant workers and HIVIAIDS vulnerability study Thailand. Bangkok, 1999. 